$\begin{aligned} & \text { LA-UR- } 98 \mathrm{~g} 984 \\ &-\quad \text { Title: } \begin{array}{l}\text { ANALYSIS OF SEQUENTIAL } \\ \text { EXCHANGES BETWEEN VULNERABLE } \\ \text { FORCES }\end{array}\end{aligned}$

Submitted to:

For discussions outside the Laboratory

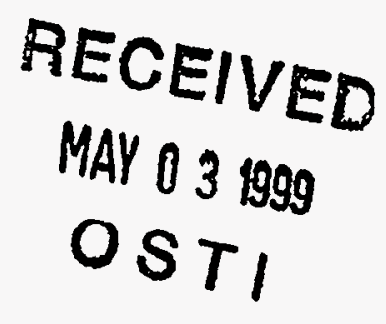

Author(s): Gregory H. Canavan, P-DO

MASTER

Date: 4 September 1998

DISTRIOUTION OF THS DOCUMEAT IS UALMTIED

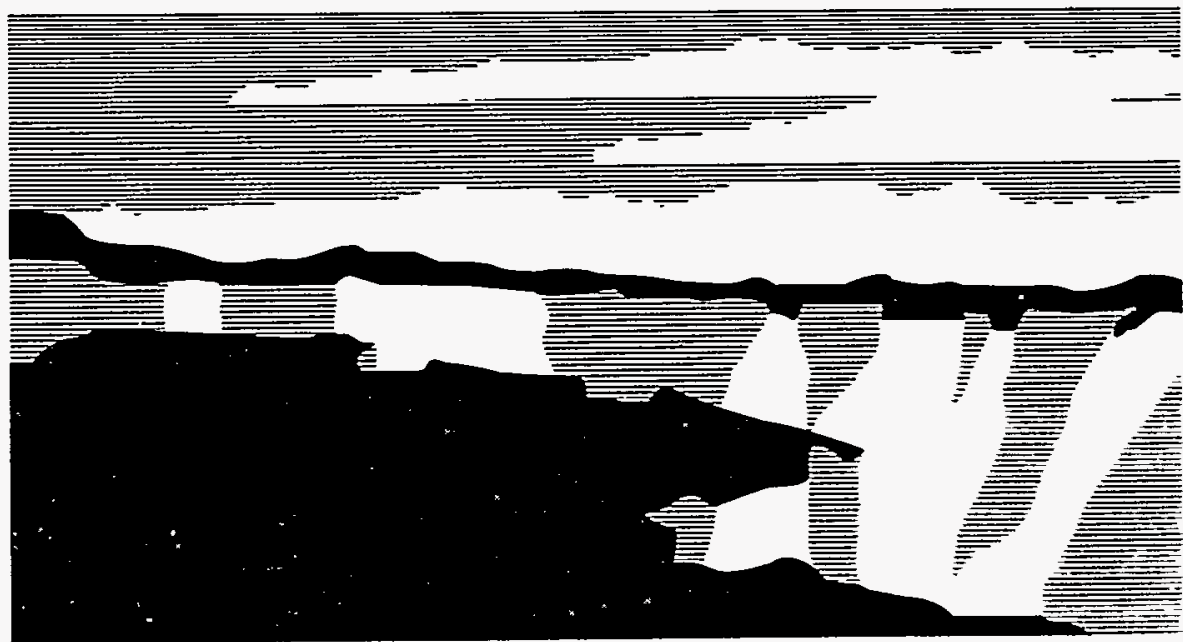

Los Alamos National Laboratory, an affirmative action/equal opportunity employer, is operated by the University of California for the U.S. Department of Energy under contract W-7405-ENG-36. By acceptance of this sticle, the publisher recognizes that the U.S. Government retains a nonexclusive, royalty-free license to publish or reproduce the published form of this contribution, or to allow others-to do so, for U.S. Government purposes. The Los Alamos National Laboratory requests that the publisher identify this article as work performed under the auspices of the U.S. Department of Energy. 


\section{DISCLAIMER}

This report was prepared as an account of work sponsored by an agency of the United States Goverament Neither the Unired States Governmeat nor any agency thereof, nor any of their employees, makes any warranty, express or implied, or assumes any legal liability or responsibility for the zecuracy, completeress, or usefulness of any information, apparatus, produce, or process disclosed. or represents that its use would not infringe privately owned rights. Reference berein 20 any specific commercial produch, process, or service by trade name, tradernark, inanufacturer, or otherwise does aot aecessarily constitute or imply its endorsemeah. recommendation, or favoring by the Unired States Governmeat or any agency thereof. The views and opinions of authors expressed herein do not necessarily saste or reflect those of the United States Government or any agency thereof. 


\section{DISCLAIMER}

Portions of this document may be illegible in electronic image products. Images are produced from the best available original document. 


\title{
ANALYSIS OF SEQUENTIAL EXCHANGES BETWEEN VULNERABLE FORCES
}

\author{
Gregory H. Canavan
}

\begin{abstract}
A multi-stage and -step analysis of sequences of crises or exchanges shows that aggressiveness on one side can induce rapid counter-value strikes by the other as well and knowledge that opponents will later become less aggressive does not mitigate the tendency to strike early in crises.
\end{abstract}

The single-strike, first strike formalism developed earlier is extended to treat multi-stage and -step sequences of crises or exchanges. ${ }^{1}$ For unsymmetric objectives, aggressiveness on one side can induce rapid counter-value strikes by the other as well. For symmetric forces and objectives, non-aggressive opponents do not engage, while aggressive opponents strike to the maximum against value. The knowledge that opponents will later become less aggressive does not mitigate the tendency to strike early in crises, which is surprising in view of the fact that inter-stage optimization provides a rudimentary knowledge of the future and hence an appreciation of the marginal cost reductions obtained.

Exchange Model. The illustration uses an simplified version of a aggregated, probabilistic treatment of the interaction between two vulnerable missile forces denoted by prime and unprime, in which outcomes are evaluated in terms of the first and second strikes each side could deliver. Each side initially has $\mathrm{M}=\mathrm{M}^{\prime}=100$ vulnerable missiles with $\mathrm{m}=3$ weapons each and $1 / \mathrm{k} \sim 100$ value targets at risk; thus, the weapons could saturate either the missile launchers or value targets. At each step the unprime side launches $\mathrm{dM}$ missiles, a fraction $\mathrm{f}$ of which is directed towards the other side's remaining vulnerable missiles. which gives a counter force attack of

$$
r=f m d M / M \text {, }
$$

The remaining weapons constitute a first strike on value targets of magnitude

$$
F=(1-f) m d M,
$$

The average survival probability of a prime vulnerable missile is $Q^{\prime} \approx q^{r}$, where $p=1$ - $q$ is the missile single shot probability of kill. Prime's $r$ ' and $Q$ are found by conjugating Eqns. (1) and (2). Thus, unprime and prime's missiles decrease as

$$
\begin{aligned}
& \mathrm{d} M / d t=-d M-m^{\prime} d M^{\prime}\left(1-Q^{\prime}\right), \\
& d^{\prime} M^{\prime} / d t=-d M^{\prime}-m d M(1-Q),
\end{aligned}
$$

where the variable $t$ can be interpreted as either time or as the step in a multi-stage sequence of conflicts and exchanges. At each step, each attacker minimizes the cost for that step and the whole sequence, which might be terminated at any step, by minimizing the cost of executing the 
next exchange or abstinence. As the exchange is a series of sequential interactions, the notion of a second strike no longer appears explicitly.

Costs and indices. The results of strikes are converted into strike costs through exponential approximations to the fractions of military value targets destroyed. The cost of damage to self, $1-\exp (-k S)$, and incomplete damage to other, $\exp (-\mathrm{kF})$, are combined with a weighting parameter $\mathrm{L}$, which measures the attacker's relative preference for causing damage to the other and preventing damage to self, ${ }^{2}$ which produces a normalized strike cost

$$
(1+\mathrm{L}) \mathrm{C}_{1} \approx[1-\exp (-\mathrm{kS})+\mathrm{L} \exp (-\mathrm{kF})] /(1+\mathrm{L}) \text {, }
$$

whose integral over $t$ is the relevant stability index for extended engagements.

Sensitivity to $L$. The damage preference $L$ is the dominant parameter for single-stage engagements. It is also the dominant parameter for multistage engagements. For symmetric forces and damage preferences, for $\mathrm{L}<1$, there is no exchange in any stage of the calculations. For $\mathrm{L}>1$, both sides exhaust their missiles by strikes on the other's value, in close accord with the single-stage calculations presented earlier.

Figure 1 shows the missiles $M$ and strikes $d M$ as functions of step or time for $L=0.9$ and $L^{\prime}=2$, i.e., prime much more aggressive than unprime. Both strikes are at $d M=15 / \mathrm{step}$, the maximum allowed in the calculation, for the first 5 steps. They then fall, although prime has a strike in the final period. Throughout, $f=f^{\prime}=0$, i.e., all of the strikes are on value. There is no attempt to damage limit by either side. The fact that one side is below the $L=1$ level that is the stability separator for spasm exchanges does not prevent an exchange in multi-step engagements.

Figure 2 shows the resulting costs. The cost to prime decreases monotonically through step 6, after which he no longer strikes. The costs to unprime increase monotonically through step 7, after which he strikes, lowering his costs and raising prime's. By following their optimal competitive strategies, prime achieves a cost of $\sim 0.4$, and unprime a cost of $\sim 0.5$. If neither struck at all, unprime's cost would be $\sim 0.9 / 1.9 \sim 0.47$ and prime's would be $\sim 2 / 3 \sim 0.67$.

Figure 3 shows $L=L$ ' for symmetric forces from a calculation in which $L$ decreases monotonically as shown to approximate the relaxation of tension between two heavily armed rivals who are initially hostile, such as might be the case in regional configurations. As $L$ falls, $L$ $f$ is $\sim 0$, i.e., strikes are on value, until $L$ reaches $\sim 1.25$. Then $f$ increases to 1 , where it remains until $\mathrm{L}$ falls below 0.75 . This implies that the most bothersome region from the perspective of the incentive to damage limit is for L close to unity.

Figure 4 shows the corresponding $M, d M$, and cumulative damage $\int_{0}^{t} d M$ as functions of step. The missile strikes are constant at $\sim 10$, the maximum allowed for the first 4 steps, then they drop to almost zero. As a result, the number of missiles drops quickly to about 40 through expenditure by $t=4$ and slowly by attrition thereafter. Thus, the bulk of the cumulative value damage is done by $t=3$. Only about half of each sides' missiles are expended, and according to 
Fig. 3, they are almost all expended on value. Only the small attacks during $t=5$ to 8 are on missiles for damage limiting, which is counter-intuitive.

Figure 5 shows the resulting costs. The top line is the total strike cost. $\mathrm{C}_{10}$ is the cost due to incomplete fulfillment one's damage objective on the other. $\mathrm{C}_{1 \mathrm{~s}}$ is the cost due to damage to self. The top line is the total strike cost $\mathrm{C}_{1}=\mathrm{C}_{10}+\mathrm{C}_{1 s}$. The cost of incomplete damage to other falls as damage cumulates through step 3. The cost of damage to self increases for the same reason. Their sum has a minimum at step 3 and then increases because beyond that point there are no more strikes, so $C_{10} \sim L /(1+L) \sim L$ as $L$ falls, while $C_{1 s} \sim 1 /(1+L)$ increases. This behavior is somewhat sensitive to the normalization of the index on $L$.

Summary and conclusions. This note extends the single-strike, first strike formalism developed earlier to treat multi-stage and multi-step sequences of crises or and observes the consequences for symmetrical and unsymmetrical objectives and forces. For unsymmetric objectives, aggressiveness on one side can induce rapid counter-value strikes by the nonaggressive side as well. Both sides pay a large price in damage to value for marginal reductions in cumulative strike costs. For symmetric forces and objectives, non-aggressive opponents do not engage, while aggressive opponents strike to the maximum against value. As both sides' damage preference is reduced, they initially strike strongly against value. The fact that they will later become less aggressive does not mitigate that tendency. In the later phase they strike weakly against forces to limit damage. Of these results, perhaps the most surprising is that inter-stage optimization, i.e., rudimentary knowledge of the future, does not delay strikes. Attempts to discount future conflicts would probably worsen this problem.

\section{References}

'G. Canavan, "Stability of Unsymmetric Forces," Los Alamos report LA-UR-97-1133, March 1977

2. G. Kent and R. DeValk, "Strategic Defenses and the Transition to Assured Survival," RAND Report R-3369-AF, October, 1986. 


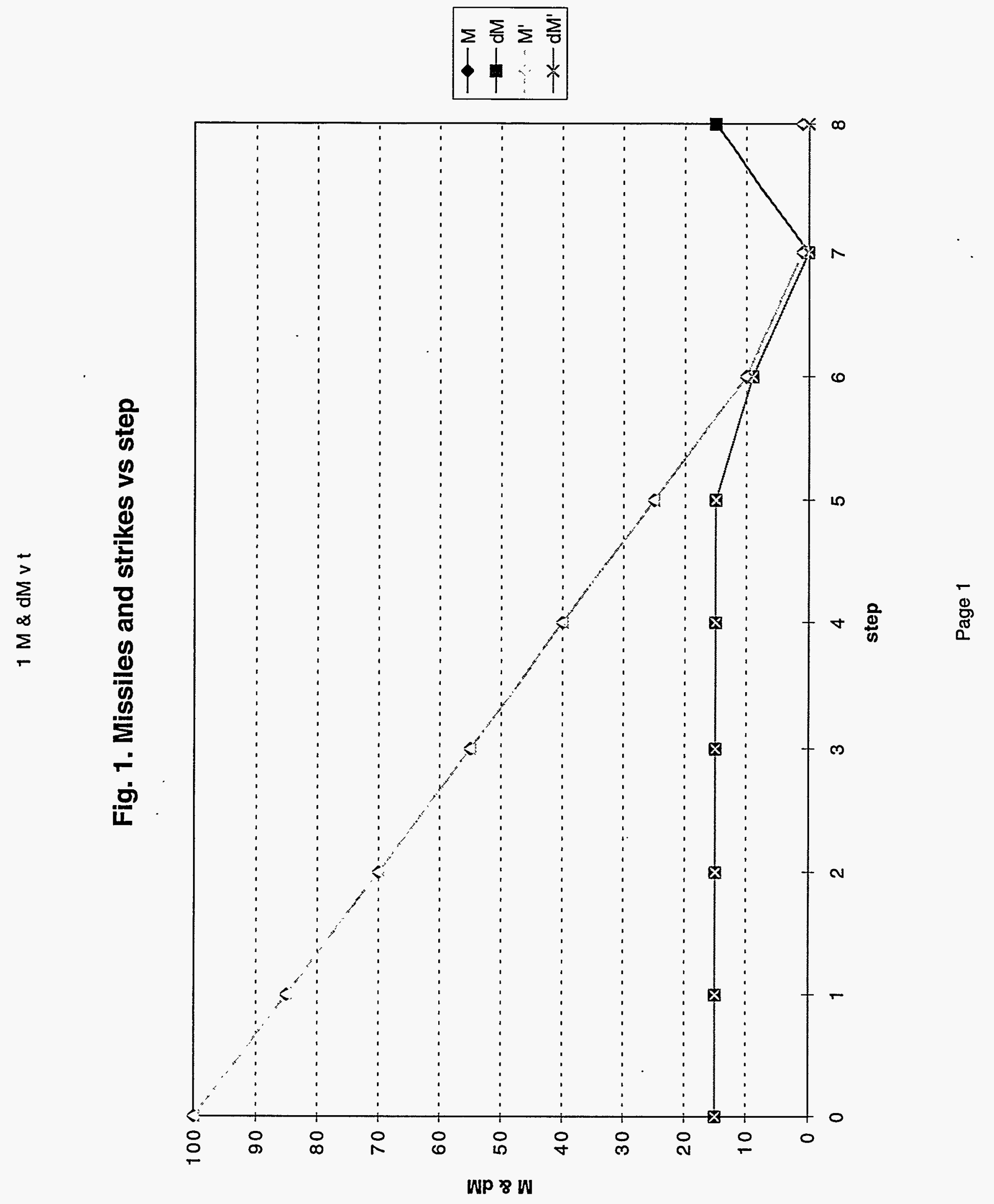




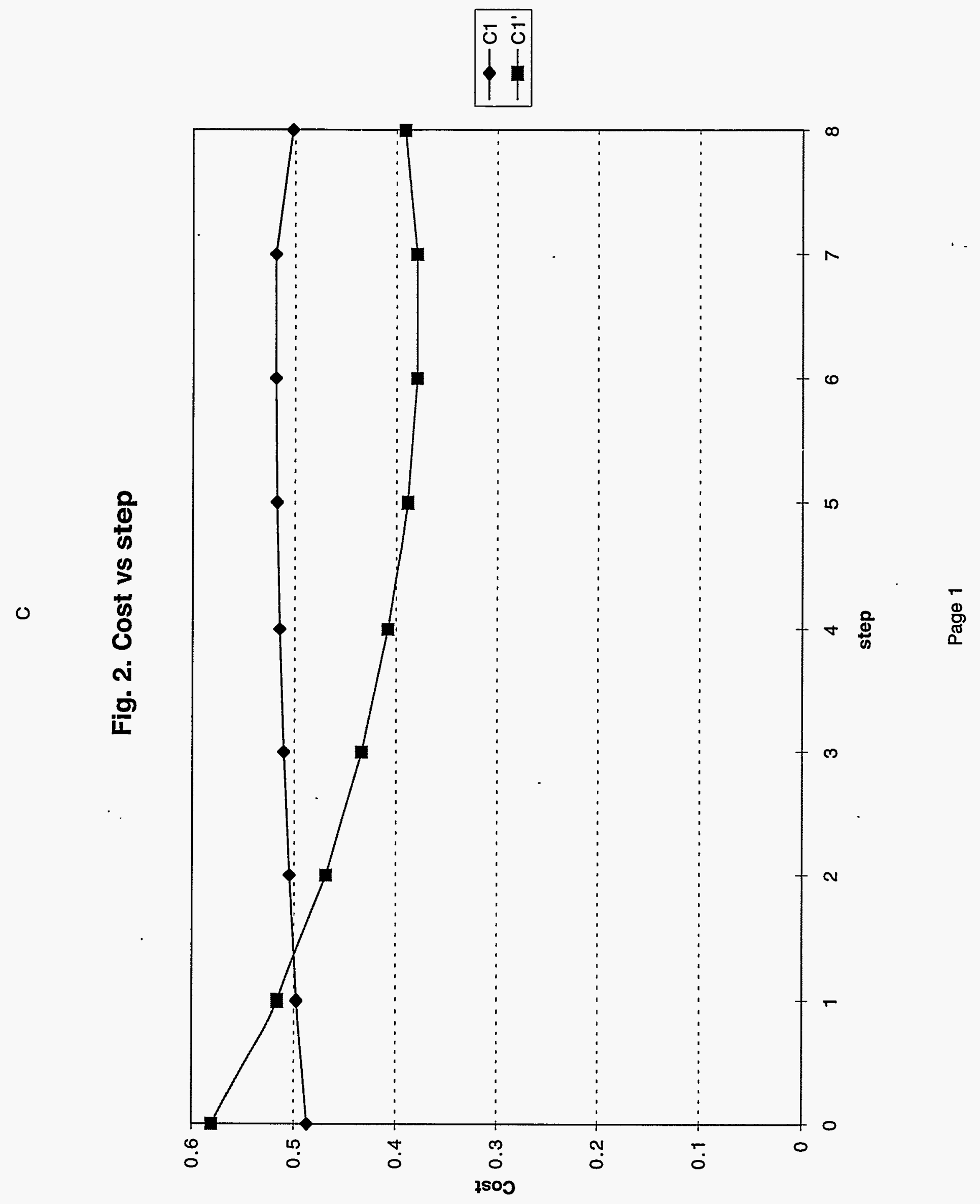




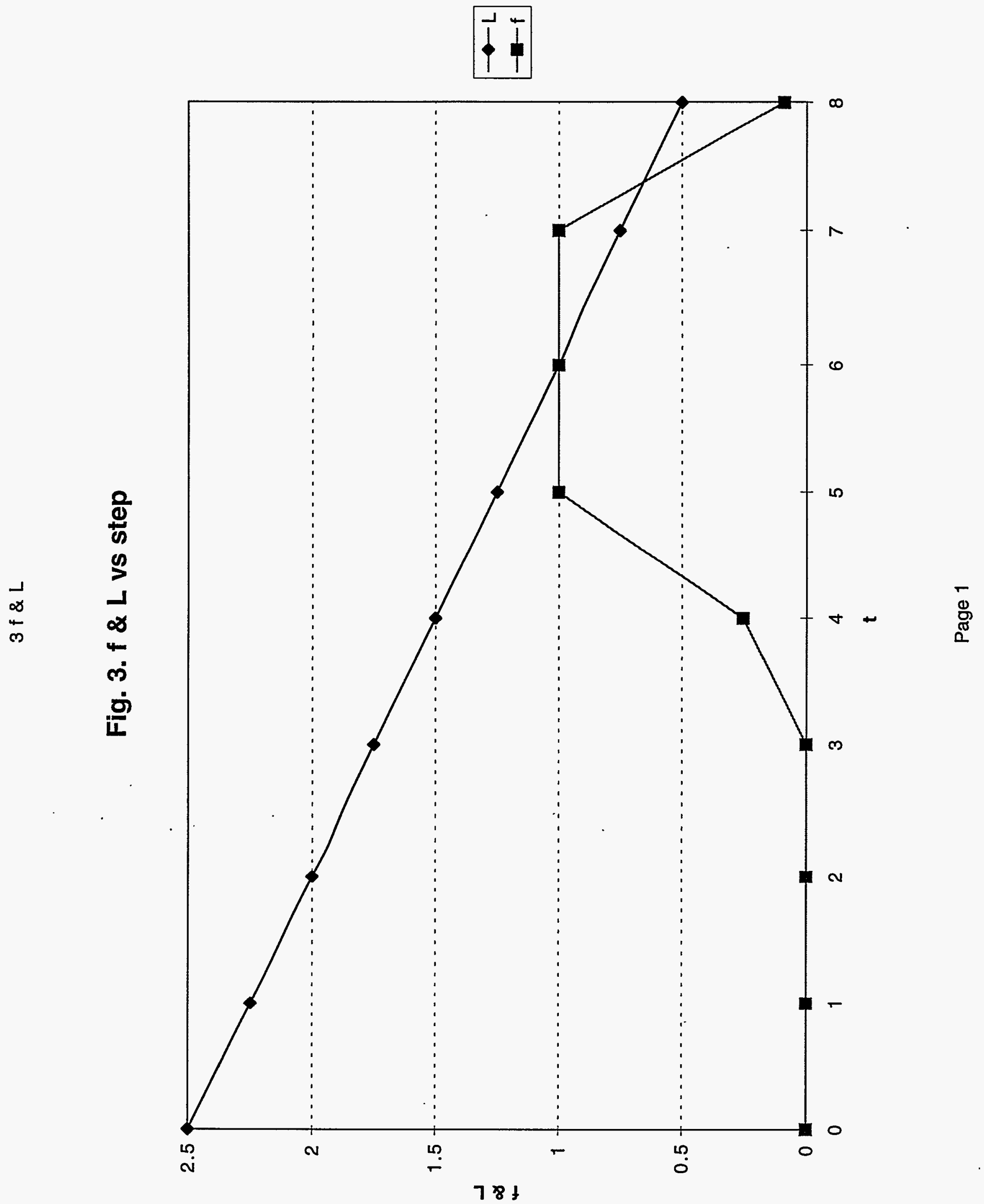




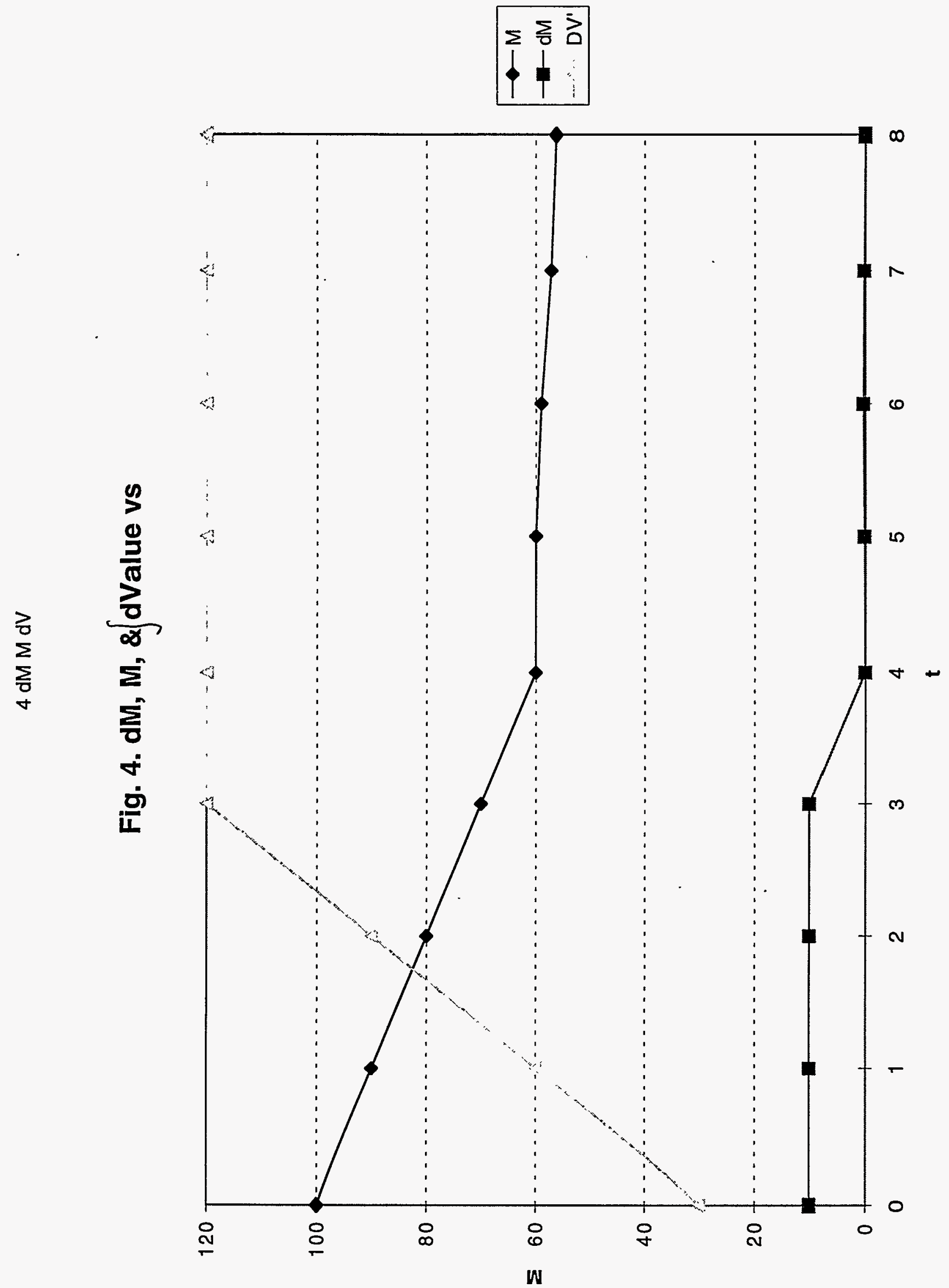




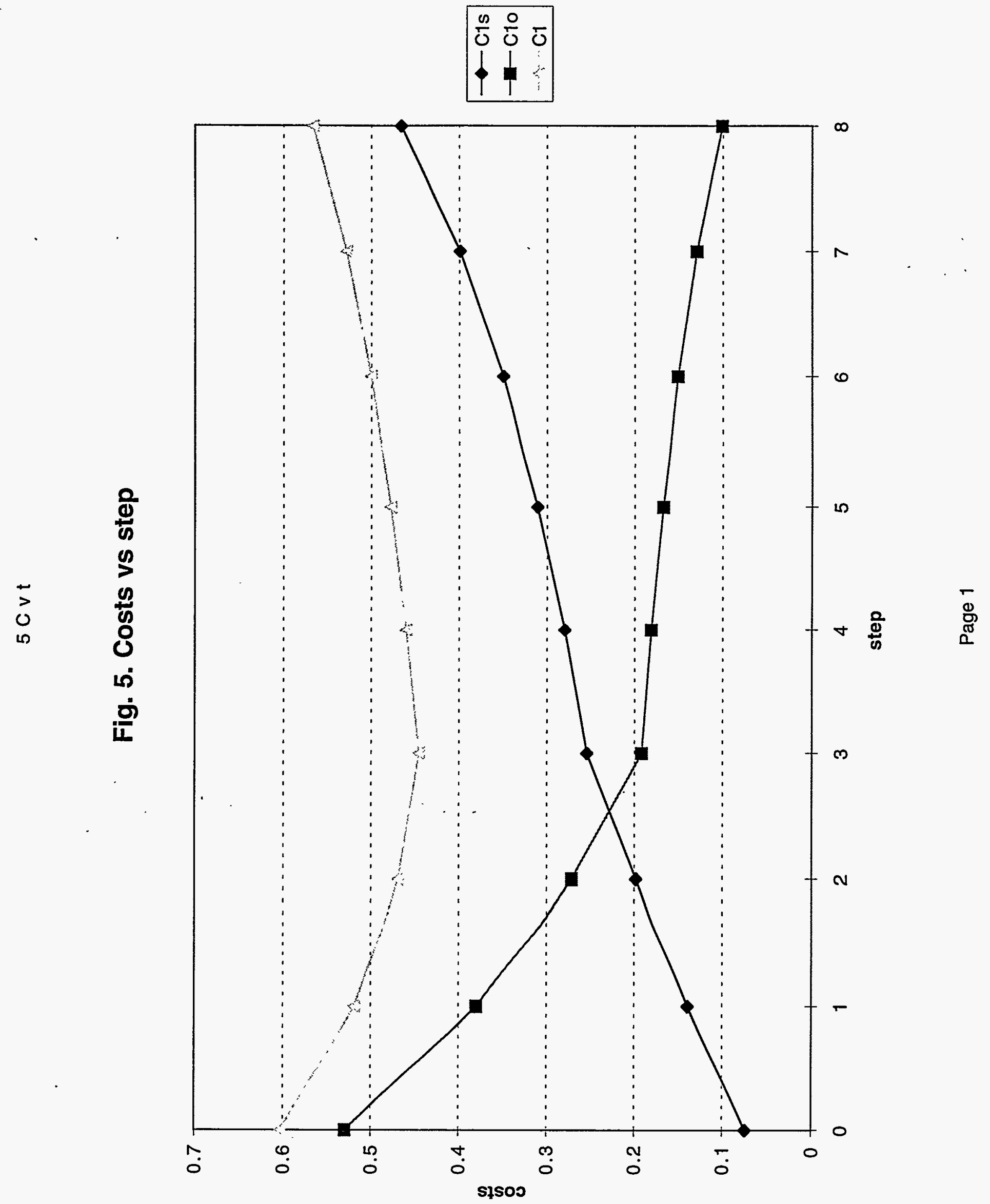

